\title{
Characterization of the chicken T cell receptor $\gamma$ repertoire by high-throughput sequencing
}

Tongtong Zhang, Qian Li, Xiaoqing Li, Li Kang, Yunliang Jiang ${ }^{*}$ and Yi Sun ${ }^{*}$

\begin{abstract}
Background: As one of " $\gamma \delta$-high" species, chicken is an excellent model for the study of $\gamma \delta$ T cells in nonmammalian animals. However, a comprehensive characterization of the TCR $\gamma \delta$ repertoire is still missing in chicken. The objective of this study was to characterize the expressed TCRy repertoire in chicken thymus using highthroughput sequencing.
\end{abstract}

Methods: In this study, we first obtained the detailed genomic organization of the TCRy locus of chicken based on the latest assembly of the red jungle fowl genome sequences (GRCg6a) and then characterized the TCRy repertoire in the thymus of four chickens by using 5' Rapid Amplification of CDNA Ends (5' RACE) along with high-throughput sequencing (HTS).

Results: The chicken TCRY locus contains a single $C_{Y}$ gene, three functional Jy segments and $44 V_{Y}$ segments that could be classified into six subgroups, each containing six, nineteen, nine, four, three and three members. Dot-plot analysis of the chicken TCRY locus against itself showed that almost all the entire zone containing $V_{Y}$ segments had arisen through tandem duplication events, and the main homology unit, containing 9 or $10 V_{Y}$ gene segments, has tandemly duplicated for four times. For the analysis of chicken TCRY repertoire, more than 100,000 unique $V_{Y}$-region nucleotide sequences were obtained from the thymus of each chicken. After alignment to the germline $V_{Y}$ and $J_{Y}$ segments identified above, we found that the four chickens had similar repertoire profile of TCR $\gamma$. In brief, four $V_{\gamma}$

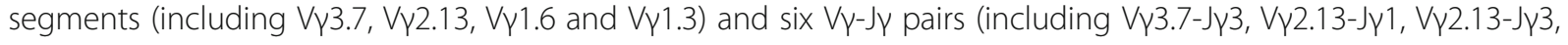

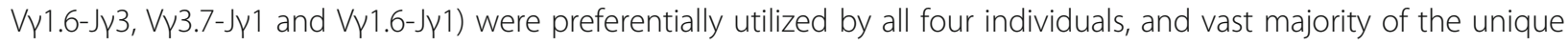
CDR3y sequences encoded 4 to 22 amino acids with mean 12.90 amino acids, which exhibits a wider length distribution and/or a longer mean length than CDR3y of human, mice and other animal species.

Conclusions: In this study, we present the first in-depth characterization of the TCRy repertoire in chicken thymus. We believe that these data will facilitate the studies of adaptive immunology in birds.

Keywords: Chicken, TCRY locus, High-throughput sequencing, CDR3y

\footnotetext{
*Correspondence: zhaojy@sdau.edu.cn; sunyi@sdau.edu.cn

Shandong Provincial Key Laboratory of Animal Biotechnology and Disease Control and Prevention, Shandong Agricultural University, 61 Daizong Street,

Shandong Province 271018 Taian City, People's Republic of China
}

(c) The Author(s). 2021, corrected publication 2021. Open Access This article is licensed under a Creative Commons Attribution 4.0 International License, which permits use, sharing, adaptation, distribution and reproduction in any medium or format, as long as you give appropriate credit to the original author(s) and the source, provide a link to the Creative Commons licence, and indicate if changes were made. The images or other third party material in this article are included in the article's Creative Commons licence, unless indicated otherwise in a credit line to the material. If material is not included in the article's Creative Commons licence and your intended use is not permitted by statutory regulation or exceeds the permitted use, you will need to obtain permission directly from the copyright holder. To view a copy of this licence, visit http://creativecommons.org/ licenses/by/4.0/. The Creative Commons Public Domain Dedication waiver (http://creativecommons.org/publicdomain/zero/1. 0/) applies to the data made available in this article, unless otherwise stated in a credit line to the data. 


\section{Background}

$\mathrm{T}$ cells are the central component of the adaptive immune system that is present in all studied jawed vertebrates. The cellular immune system which mediated by $\mathrm{T}$ cells visualizes the world of pathogens largely through its $\mathrm{T}$ cell immune receptors [1]. Conventional $\mathrm{T}$ cell receptors (TCRs) are disulfide-linked heterodimers that are composed by either $\alpha$ and $\beta$ chains or $\gamma$ and $\delta$ chains, which are co-expressed on the surface of two $\mathrm{T}$ cell subpopulations, $\alpha \beta$ and $\gamma \delta$ T cells, respectively [2]. Each $\mathrm{T}$ cell receptor polypeptide is composed of two functional domains: variable region which is capable of recognizing foreign molecular patterns and constant regions which can anchor the receptors in the $\mathrm{T}$ cell membrane. During the intrathymic $\mathrm{T}$ cell development, the variable region that is unique to each $\mathrm{T}$ cell is assembled via somatic recombination of variable $(\mathrm{V})$, diversity (D) and joining $(\mathrm{J})$ gene segments for $\beta$ and $\delta$ chains, and of $\mathrm{V}$ and $\mathrm{J}$ gene segments for $\alpha$ and $\gamma$ chains. The antigen specificity of each TCR is largely determined by the complementarity determining region 3 (CDR3) loop, which is encoded by the junctional site of $\mathrm{V}(\mathrm{D}) \mathrm{J}$ rearrangement and is the most varied portion of the TCR molecule $[3,4]$.

Although $\gamma \delta$ T cells represent only a small proportion of the $\mathrm{CD}^{+}$lymphocytes in the circulation and most tissues in human and mice (" $\gamma \delta$-low" species), they play vital roles as a bridge to connect innate and adaptive immune function. Unlike the antigen recognition by $\alpha \beta \mathrm{T}$ cells, $\gamma \delta \mathrm{T}$ cells seem to bind antigens in non-MHCrestricted manners, and the CDR3 length distibutions of the TCR $\gamma$ and $\delta$ indicated that the $\gamma \delta$ TCRs may recognize antigen in ways similar to that of antibodies. Therefore, $\gamma \delta$ T cells may be more flexible than the classical $\alpha \beta \mathrm{T}$ cells in mediating cellular immunity [5]. As " $\gamma \delta$-high" species, chicken, rabbit and artiodactyls have high proportion of $\gamma \delta$ T cells among circulating lymphocytes. In chickens, the percentage of $\gamma \delta$ T cells can reach up to $50 \%$ of isolated lymphocytes of peripheral blood and organs [6]. However, the functions of $\gamma \delta \mathrm{T}$ cells have not been well studied in these " $\gamma \delta$-high" species. As one of " $\gamma \delta$-high" species and the best-studied nonmammalian model for immunological research, chicken is an excellent candidate for further study of $\gamma \delta \mathrm{T}$ cells. Elucidating the repertoire diversity of chicken TCR genes will surely provide fundamental information for further understanding the functions of $\gamma \delta$ T cells in " $\gamma \delta$ high" species.

At present, the reference germline sequences for the $\mathrm{V}, \mathrm{D}$ and $\mathrm{J}$ gene segments of chicken TCR $\gamma$ locus is not found in the international ImMunoGeneTics information system (IMGT, http://www.imgt.org) [7]. Previous studies reported that the chicken TCR $\gamma$ locus has three $\mathrm{J} \gamma$ gene segments, a single $\mathrm{C} \gamma$ gene and three $\mathrm{V} \gamma$ subgroups, each of which includes approximately 8-10 members [8]. Recently, Liu et al. re-sequenced a bacterial artificial chromosome (BAC) clone 174P24 ( $205 \mathrm{~kb})$ that covers the red jungle fowl (Gallus gallus) TCRy locus by using cross-reference error-correction sequencing approach, Illumina and single-molecule real-time sequencing technology and analyzed the genomic organization of the chicken $T C R \gamma$ locus; however, they did not provide the complete sequence of this BAC clone as well as the detailed germline sequences or locations of each $\mathrm{V} \gamma$ and $\mathrm{J} \gamma$ fragments [9].

To obtain a relative complete germline gene database as the basis for downstream repertoire analysis of the chicken TCR , we focused on the latest assembly of the red jungle fowl genome sequences (GRCg6a, released on Apr 2018, GCA_000002315.5), which was sequenced and assembled with single molecule real time (SMRT) sequencing technology to a depth of approximately $80 \times$. Fortunately, the chromosome region containing $T C R \gamma$ locus possesses few gaps. Therefore, in this study, we first obtained the detailed genomic organization of the red jungle fowl TCR $\gamma$ locus based on these high-quality genome sequences, and then characterized the TCR $\gamma$ repertoire in chicken thymus by using 5' Rapid Amplification of cDNA Ends (5' RACE) along with highthroughput sequencing (HTS).

\section{Methods}

Identification of germline $V_{\gamma}$ and $J \gamma$ gene segments

Chicken germline $\mathrm{C} \gamma$ sequence (GenBank accession numbers AB092341) was used as query to retrieve the latest chicken genomic sequences (GRCg6a) by a tBLASTn approach in the GenBank database (www.ncbi. nlm.nih.gov/assembly/GCF_000002315.5/) [10]. To determine the location of the $\mathrm{V} \gamma$ gene segments, the genomic sequence ( $100 \mathrm{~kb}$ length) located upstream of the $\mathrm{C} \gamma$ gene was screened using IgBLAST (www.ncbi. nlm.nih.gov/igblast/) [11]. Sequences that matched mouse (or human) $\mathrm{V} \gamma$ segments with an E-value $<10^{-3}$ were further analyzed for chicken $\mathrm{V}_{\gamma}$ genes.

\section{Nomenclature of germline $\mathrm{V}_{\boldsymbol{\gamma}}$ and $\mathrm{J} \gamma$ gene segments}

Since the previous studies have identified three $\mathrm{V}_{\gamma}$ subgroups [8], in this study we numbered the germline $\mathrm{V} \gamma_{\gamma}$ subgroups according to the previous studies, that is, the $\mathrm{V} \gamma 1, \mathrm{~V} 2$ and $\mathrm{V} \gamma 3$ subgroups numbered in this study is one-by-one corresponding to the $\mathrm{V} \gamma 1, \mathrm{~V} \gamma 2$ and $\mathrm{V} \gamma 3$ subgroups numbered in previous studies. Within each subgroup, $\mathrm{V} \gamma$ segments are named sequentially in directions from 3 ' to $5^{\prime}$ with the subgroup number followed by the gene segment number. Potentially functional, ORF and pseudo-V segments were identified according to the IMGT standards [12]. The V gene domains (framework regions or complementarity-determining regions, FRs or 
CDRs) were classified using the IMGT numbering system [13]. The alignment and comparison of DNA (and protein) sequences of $\mathrm{V} \gamma$ segments were performed with DNASTAR lasergene software suite [14] and GeneDoc [15].

\section{Phylogenetic analyses of germline $V_{\gamma}$ gene segments}

Phylogenetic tree of $\mathrm{V} \gamma$ and $\mathrm{J} \gamma$ segments was constructed in MEGA version X [16] using the maximum likelihood method with 1,000 bootstrap replicates, and phylogenetic trees of chicken $\mathrm{V} \gamma^{2}$ segments were constructed using neighbor joining method with 1,000 bootstrap replicates. Only the FR1 through 3 regions (as defined by the IMGT numbering system) of each V sequence were utilized to construct the phylogenetic tree. Multiple nucleotide alignments for the tree construction were performed using ClustalW. Each V subgroup is represented by one sequence per species chosen at random from the functional genes. The accession numbers of $\mathrm{V}$ sequences used in this study (except for chicken sequences) are listed in Additional file 1. Chicken sequences were derived from this study.

\section{Dot plot analyses}

Dot plot analyses of red jungle fowl against itself or duck $T C R \gamma$ loci were conducted with dotmatcher (http:// emboss.bioinformatics.nl/cgi-bin/emboss/dotmatcher/) [17]. The window size is $300 \mathrm{bp}$ and the identity threshold is $70 \%$.

\section{Sample collection, RNA isolation, reverse transcription and quantitative real-time polymerase chain reaction (qRT-PCR)}

Four healthy Hy-line Brown commercial hens at the ages of 30 days and 300 days each were purchased from a local chicken farm in Taian city and utilized for isolating total RNA from 13 (30-days-old chicken) or 15 (300days-old chicken) tissues to analyze the expression pattern of the chicken $T C R \gamma$ gene.

Total RNA was extracted from various tissues using RNAsimple Total RNA Kit (Tiangen Biotech, Beijing, China). Reverse transcription was conducted using PrimeScript RT reagent kit with a gDNA Eraser (TaKaRa, Dalian, China). The mRNA expression level of TCRy was measured by qRT-PCR with primers $(C \gamma F$ and $C \gamma R$, see Additional file 2) designed according to the mRNA sequence of chicken $\mathrm{C} \gamma$ segment. The chicken GAPDH gene was used as the internal control with primers GAPDHF and GAPDHR (see Additional file 2). qRTPCR was performed using SYBR Premix Ex Taq (TaKaRa, Dalian, China) on an MX3000p instrument (Stratagene, La Jolla, CA, USA) according to the following conditions: $95{ }^{\circ} \mathrm{C}$ for $30 \mathrm{~s} ; 40$ cycles of $95{ }^{\circ} \mathrm{C}$ for $5 \mathrm{~s}$, $53{ }^{\circ} \mathrm{C}$ for $30 \mathrm{~s}$, and $72{ }^{\circ} \mathrm{C}$ for $15 \mathrm{~s}$; and a final stage $95{ }^{\circ} \mathrm{C}$ for $1 \mathrm{~min}, 58{ }^{\circ} \mathrm{C}$ for $30 \mathrm{~s}$, and $95{ }^{\circ} \mathrm{C}$ for $30 \mathrm{~s}$. The relative expression levels of a sample were determined using the $2^{-\Delta \Delta C t}$ method by comparing the values with the internal control. Each sample was amplified in triplicate.

\section{$5^{\prime}$ rapid amplification of CDNA ends (5' RACE)}

To get the expression diversity of TCR $\gamma$, total RNA was isolated from the thymus of Hy-line Brown commercial hens at the ages of 30 days using a TRIzol Reagent (Ambion, CA, USA) according to the manufacturer's instruction. The expressed VJ repertoire of TCR $\gamma$ was obtained by the $5^{\prime}$ RACE method using the SMARTer RACE 5'/3' Kit (Takara, CA, USA). RACE semi-nested PCR was performed with the forward universal UPM primer and a $\mathrm{C} \gamma$-specific reverse primer within the first exon of $\mathrm{C} \gamma$ (GSP1, see Additional file 2). A unique sequence barcode of 12 nt length was placed at the $5^{\prime}$ end of each GSP1 in order to identify reads that originate from a particular sample (see Additional file 2). All PCR amplifications were performed using two high fidelity enzymes, TransStart FastPfu DNA polymerase (TransGen Biotech, Beijing, China) and PrimeSTAR HS DNA Polymerase (Takara, CA, USA). The detailed protocol for preparation of unbiased TCR cDNA libraries for HTS could refer to the reference [18].

\section{Library preparation, HTS and data analysis}

Library preparation, HTS and data analysis were performed by Beijing Tangtang Tianxia Biotechnology Co., Ltd. Briefly, the 5' RACE PCR products were detected using agarose gel electrophoresis, and the major DNA bands with the length of $500 \sim 600$ bp were recovered and purified. PCR amplicons were then subjected to end-repair and phosphorylation using T4 DNA polymerase, Klenow DNA polymerase and T4 polynucleotide kinase (PNK). These repaired PCR amplicons were 3' adenylated using Klenow Exo- (3' to 5' exo minus, Illumina, CA, USA) and then ligated to the paired-end adapters using T4 DNA ligase (Illumina, CA, USA). Adaptor-ligated products were purified by AMPure XP beads and quantified on an Agilent Technologies 2100 Bioanalyzer. Cluster generation was performed on the cBOT using the TruSeq PE Cluster Kit v3-cBot-HS kit (Illumina, CA, USA) followed by sequencing on Illumina Novaseq 6000 in paired-end mode with a read length of $250 \mathrm{bp}$.

All of raw reads were treated with a quality control procedure to remove poor quality sequences and adaptor sequences using Cutadapt (version 1.2.1) [19]. The 3' end reads which contain the $C \gamma$-specific reverse primer for $5^{\prime}$ RACE and $250 \mathrm{bp}$ in length were aligned to the germline $\mathrm{V} \gamma$ and $\mathrm{J} \gamma$ segments identified above using a local BLAST program (version 2.2.30) and each sequence was assigned an optimal germline $\mathrm{V} \gamma$ and $\mathrm{J} \gamma$ segments. Those sequences that aligned with a pseudo- 
or ORF- germline $V_{\gamma}$ segment and redundant sequences that have identical CDR3 nucleotide sequence and use the same $V_{\gamma}$ and $J \gamma$ segments were filtered. According to the IMGT numbering system, the CDR3 of a rearranged TCR gene was defined as the region between the 2ndconserved cysteine encoded by $V_{\gamma}$ region and the PheGly-X-Gly motif encoded by JY region [13]. In all potentially functional $\mathrm{V}_{\gamma}$ segments identified above, the 2ndconserved cysteine was located in a $\operatorname{Tyr}(\mathrm{Tyr} / \mathrm{His}) \mathrm{Cys}$ motif, so DNA sequence between TAC (T/C)A(T/C) TG(T/C) (encoding Tyr(Tyr/His)Cys motif) and TT(C/ T) GG(C/A) (A/T)(C/G)(A/T) GG(A/T) (encoding PheGly-X-Gly motif) was extracted from each $\mathrm{V} \gamma$-J $\gamma$ rearranged sequences using Cutadapt (version 1.2.1) [19]. Putatively non-functional CDR3y sequences (containing frameshift indels and termination codons) were filtered and the remaining sequences were used to analyze the length distribution and amino acid (AA) composition of the CDR3y.

\section{Statistical analysis}

Microsoft Excel was used for the HTS data statistics and analysis. Diagrams were conducted using GraphPad Prism version 8.0.2 for windows.

\section{Results}

\section{Genomic organization of the chicken TCRY locus}

By annotating the latest assembly of the red jungle fowl genome sequences, we identified the $T C R y$ locus that is mapped on chromosome 2 and spans approximately $100 \mathrm{~kb}$ from the most $5^{\prime} \mathrm{V} \gamma$ gene segment to the $3^{\prime}$ untranslated region ( $3^{\prime}$ UTR) of the single $\mathrm{C} \gamma$ region (Fig. 1). The red jungle fowl TCR $\gamma$ locus has a classical translocon organization, similar to opossum (Monodelphis domestica), duck, rabbit, Chinese alligator (Alligator sinensis) and dolphin (Tursiops truncate), but different from human, mouse, Rhesus monkey (Macaca mulatta), dromedary (Camelus dromedarius), bovine, sheep, cat, dog and Atlantic salmon (Salmo salar) [20-33]. As reported previously $[8,34]$, the locus contains three functional $\mathrm{J} \gamma$ gene segments with conserved 12-bp RSS at their $5^{\prime}$ end, followed by a single $\mathrm{C} \gamma$ gene which is encoded by three exons (Fig. 1). A total of $44 \mathrm{~V} \gamma$ gene segments were identified upstream of the $\mathrm{J} \gamma$ gene segments. 28 of them are potentially functional; 13 were pseudogenes and three were defined as ORF because of lacking some conserved AA (e.g., $1^{\text {st }}$-CYS 23 , TRP 41 and $2^{\text {nd }}$-CYS 104) or RSSs compared with potentially functional $\mathrm{V} \gamma$ genes (Fig. 1).

Based on the criterion that the $\mathrm{V}$ segments belonging to the same subgroup should share at least $70 \%$ nucleotide identity, $44 \mathrm{~V} \gamma$ segments could be classified into six distinct subgroups (Table 1). Interestingly, there is no intron between the sequence encoding the leader peptide and the extracellular $\mathrm{V}$ domain in the members of $V_{\gamma} 1$ subgroup but not in the members of the other five $\mathrm{V}_{\gamma}$ subgroups. This unusual characteristic is also found in the members of chicken $V \alpha 1$ subgroup, whereas the $\mathrm{V}$ gene segments in chicken TCR $\beta$ and mammalian $T C R \gamma$ loci exhibit a typical two-exon structure $[35,36]$. Subgroup $V_{\gamma} 4, V_{\gamma} 5$ and $V_{\gamma} 6$ are only identified in germline sequences but not in cDNA sequences cloned in previous studies [8]. Subgroup V $\gamma 4$ contains three potentially functional $\mathrm{V} \gamma_{\gamma}$ segments and one pseudogene, but subgroup $\mathrm{V} \gamma 5$ and $\mathrm{V} \gamma 6$ merely contain three pseudogenes, respectively (Table 1 ). Sequence similarity between the six subgroups showed less than $55 \%$ nucleotide identity (data not shown). There are relatively higher sequences similarity within $\mathrm{V}_{\gamma} 1, \mathrm{~V}_{\gamma} 3$ and $\mathrm{V}_{\gamma} 4$ subgroups, shared more than 91.1 and $84.0 \%$ identity at

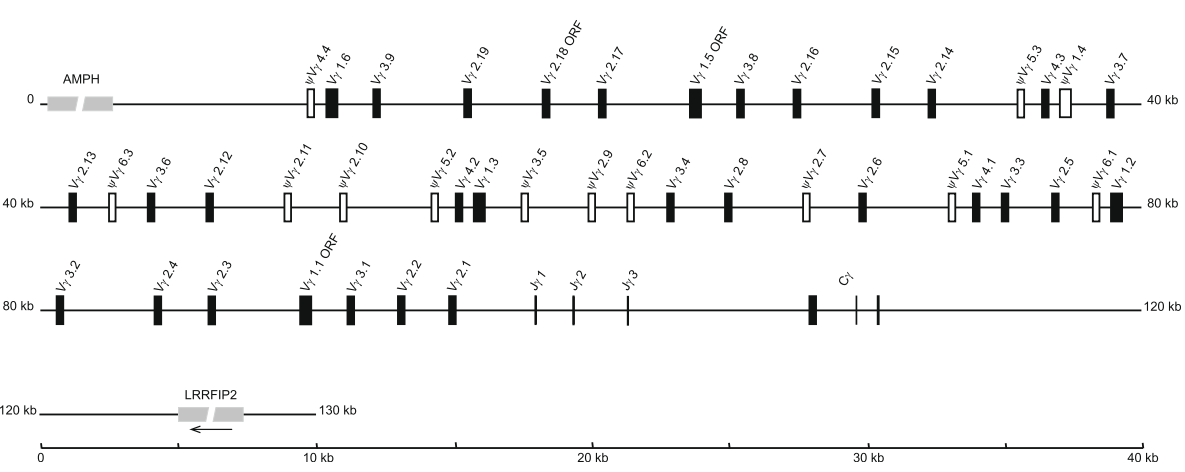

Fig. 1 Genomic organization of the red jungle fowl TCRY gene locus. $V_{\gamma}$ : potentially functional $V_{\gamma}$ gene segment; $V_{\gamma}$ ORF: $V_{\gamma}$ gene segment with an intact open reading frame but containing defect in RSS or regulatory elements, and/or absence of the conserved amino acids which are necessary for the correct folding of the $V$-region; Jy: joining gene segment; $C_{\gamma}$ : constant gene segment. Potentially functional $V_{\gamma}$ segments and $V_{\gamma}$ ORFs are represented with black boxes. Pseudo $V_{\gamma}$ segments are represented with hollow boxes and marked with the letter " $\psi$ ". Non-TCR genes located flanking TCRY locus are shown in light grey. The arrow indicates that the transcriptional orientation of LRRFIP2 gene is opposite to the CY gene segment 
Table 1 Summary of the germline $V_{Y}$ subgroups retrieved from genomic sequences of red jungle fowl (GRCg6a)

\begin{tabular}{|c|c|c|c|}
\hline$V_{Y}$ subgroup & $V_{Y}$ gene & Functional & Total \\
\hline$\overline{V_{\gamma} 1}$ & $V_{Y 1} 1.10 R F^{a}, V_{Y 1} .2, V_{Y 1} 1.3, \psi V_{Y} 1.4^{b}, V_{Y 1}$ OORF, $V_{Y 1} .6$ & 3 & 6 \\
\hline$v_{\gamma} 2$ & 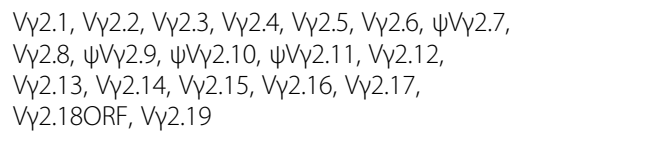 & 14 & 19 \\
\hline$v_{\gamma 3}$ & $v_{\gamma} 3.1, v_{\gamma} 3.2, v_{\gamma} 3.3, v_{\gamma} 3.4,4 v_{\gamma 3} .5, v_{\gamma 3} .6, v_{\gamma 3} .7, v_{\gamma 3} 3.8, v_{\gamma 3} .9$ & 8 & 9 \\
\hline $\mathrm{V}_{\gamma} 4$ & $V_{Y} 4.1, V_{Y} 4.2, V_{\gamma} 4.3, \psi V_{Y} 4.4$ & 3 & 4 \\
\hline$v_{\gamma} 5$ & $\psi V_{\gamma} 5.1, \psi \vee V_{\gamma} 5.2, \psi V_{\gamma} 5.3$ & 0 & 3 \\
\hline$v_{\gamma} 6$ & $\psi \vee \gamma 6.1, \psi \vee \gamma 6.2, \psi \vee \vee \gamma 6.3$ & 0 & 3 \\
\hline Total & & 28 & 44 \\
\hline
\end{tabular}

a,b The marks "ORF" and " $\psi$ " are interpreted as Fig. 1

the nucleotide and amino acid levels, respectively (data not shown, Fig. 2), but members from $V \gamma 2$ subgroup are more diverse than those from other subgroups (Fig. 2 and Additional file 3). Detailed information of each $\mathrm{V}_{\gamma}$ segment retrieved from the latest chicken genome assembly, including position, transcriptional orientation, nucleotide and amino acid sequence of $\mathrm{V} \gamma, \mathrm{J} \gamma$ and $\mathrm{C}_{\gamma}$ segments, signal peptide sequence, as well as RSS sequence are listed in Additional file 4.
Phylogenetic analysis of chicken $V_{Y}$ gene segments

The evolutionary relationship of chicken $V_{\gamma}$ genes was investigated by constructing a phylogenetic tree with maximum likelihood method using the nucleotide sequences containing FR1 to FR3 region from different tetrapods (Fig. 3). The result shows that there are clear corresponding relationships between chicken and duck $V_{\gamma}$ subgroups. The chicken $V_{\gamma} 2$ subgroup first clustered with the $V_{\gamma} 1$ and $V_{\gamma} 2$ subgroups of duck [21], and then clustered with some $\mathrm{V}_{\gamma}$

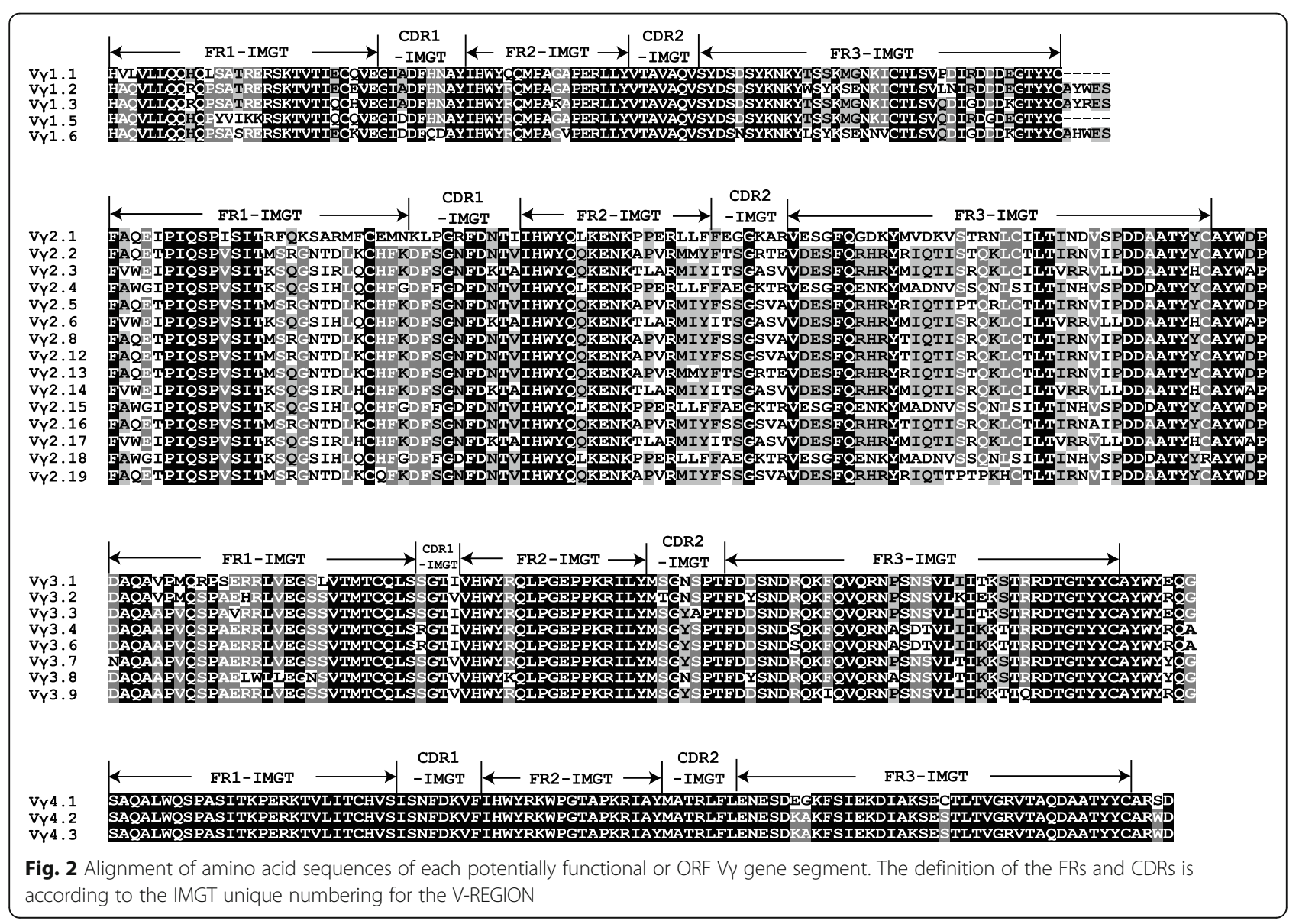




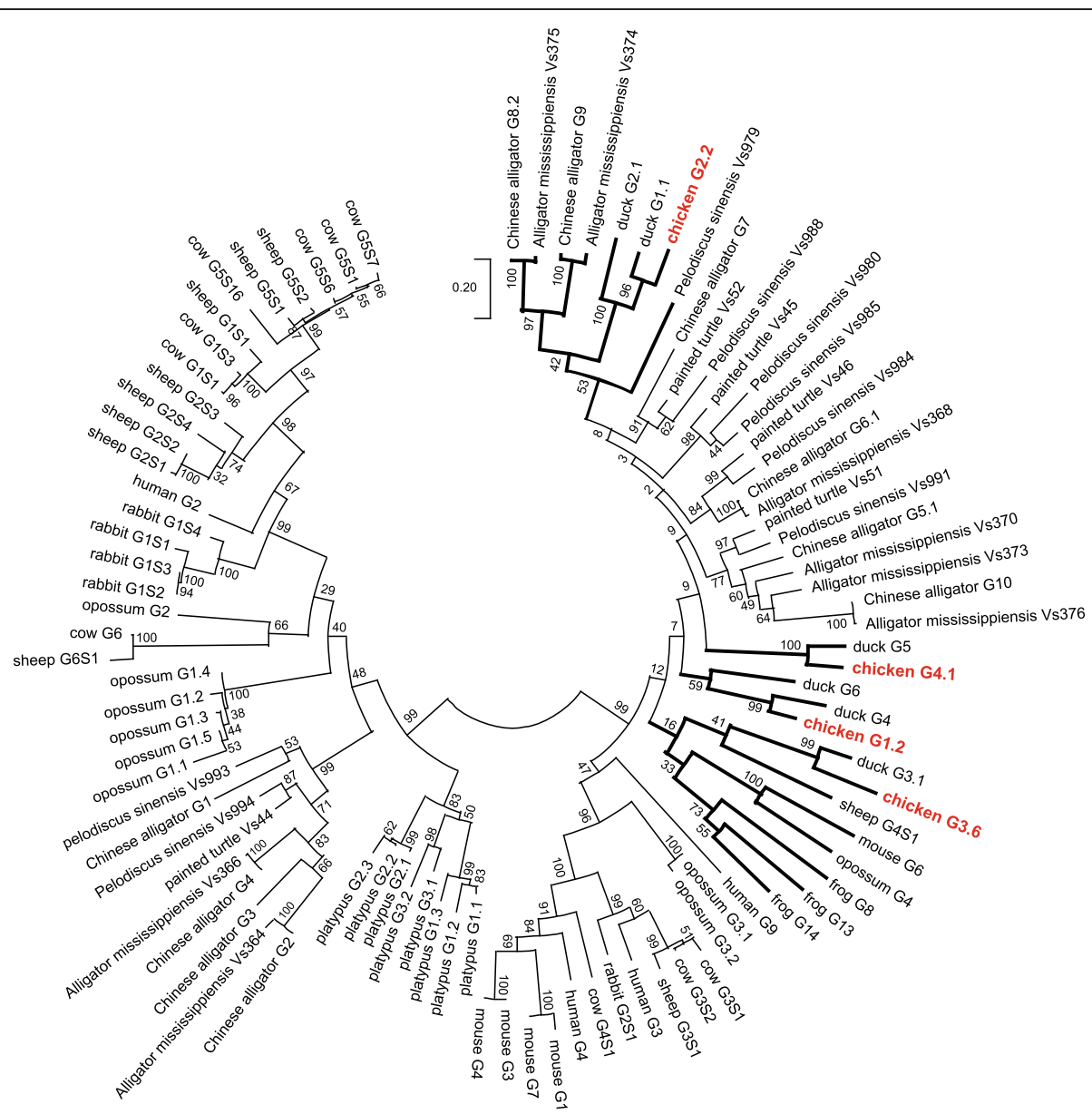

Fig. 3 Phylogenetic analysis of the $V_{Y}$ gene segments in representative tetrapod species. The phylogenetic tree was constructed using the maximum likelihood method in MEGA X with nucleotide sequences corresponding to FR1 through FR3. Branches containing chicken VY are indicated in bold, and the chicken $V_{Y}$ gene segments are marked in red. Bootstrap percentage values based on 1000 replicates are shown at the interior branch nodes. The " $G$ " in the name of each sequence means " $V \gamma^{\prime}$

subgroups from crocodiles, suggesting that these $V_{\gamma}$ subgroups may be evolved from an ancestral $V_{\gamma}$ gene that was present in the common ancestor of both birds and crocodiles. Conversely, the chicken $V \gamma 1, V_{\gamma} 3$ and $V \gamma 4$ subgroups only clustered with duck $\mathrm{V} \gamma^{4}$ (and $\mathrm{V} \gamma^{6}$ ), $\mathrm{V} \gamma^{3}$ and $\mathrm{V}_{\gamma} 5$ subgroups with more than $50 \%$ bootstrap percentage, respectively [21], but clustered with $V_{\gamma}$ genes from other tetrapods with lower bootstrap percentage, suggesting that these $V_{\gamma}$ subgroups probably emerged after the separation of birds. In general, the phylogenetic analysis of $\mathrm{V} \gamma_{\gamma}$ segments showed that most avian $\mathrm{V}_{\gamma}$ subgroups have a closer relationship with reptiles rather than mammals. But in some previous studies, chicken $\mathrm{V} \gamma 3$ first fell in the same phylogenetic clade with $\mathrm{V}_{\gamma}$ of sheep and cow and then clustered with other mammals, amphibians and/or reptiles [20-22, 37]. The discrepancy between our result and these reports, at least in part, is due to distinct sequences and methods used in phylogenetic tree construction.

\section{Dot plot analysis of the chicken TCRy locus}

To clarity the genomic structure and possible evolution mode of the chicken $T C R \gamma$ locus, the red jungle fowl $T C R \gamma$ genomic sequence was aligned against itself by dot-plot analysis (Fig. 4A). The dot-plot matrix clearly shows that a series of tandem duplication events had led to a substantial increase in the number of germline $\mathrm{V} \gamma_{\gamma}$ genes. The main homology unit, containing 9 or $10 \mathrm{V \gamma}$ gene segments, has tandemly duplicated for four times, which covers almost the entire zone of $\mathrm{V} \gamma$ genes. All four repeats are nearly identical in length $(16 \sim 18 \mathrm{~kb})$ and share more than $83.3 \%$ nucleotide identity (see Additional file 5), suggesting that they might be produced by recent duplication events. Our previous study showed that the $5^{\prime}$ part of the chicken TCR $\beta$ locus also generated from tandem duplication occurred recently [36], so tandem duplication may be a common mechanism used to construct the TCR loci in chicken. 

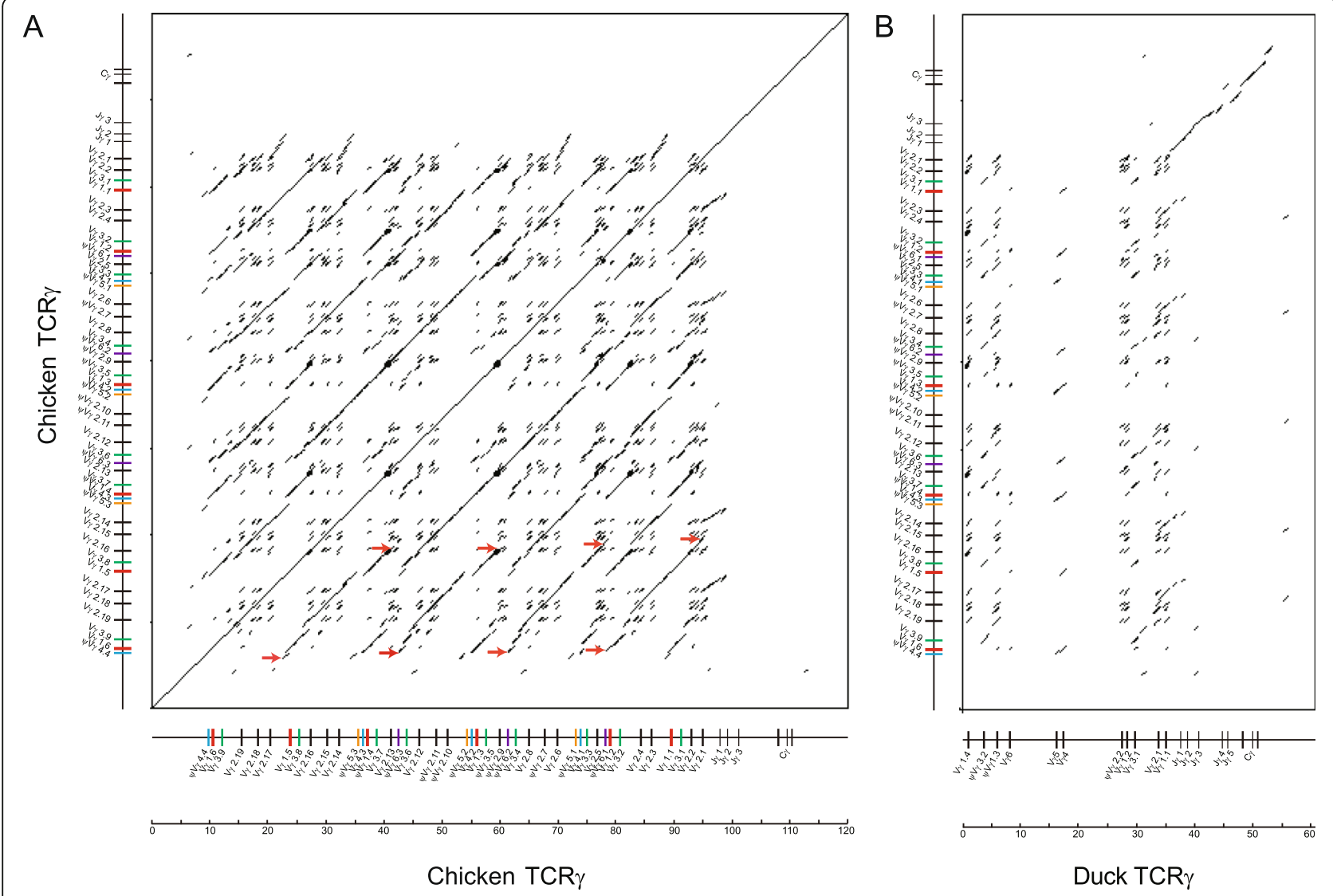

Fig. 4 Dot-plot analysis of the chicken TCRY sequence against itself or the duck TCRy sequence. The dot-plot matrices were constructed using dotmatcher with $300 \mathrm{bp}$ window size and $70 \%$ identity threshold. Dots and lines indicate the regions that showed more than $70 \%$ nucleotide similarity within the chicken TCRy locus (A) or between chicken and duck TCRy loci (B). In matrix A, the main homology units are indicated with red arrows. Different $V_{Y}$ subgroups are shown in different colors in the schematic representation of chicken TCRY locus alongside axes. $V_{Y}$ segments from $V_{\gamma} 1$ to $V_{\gamma} 6$ subgroups are depicted in red, black, green, blue, yellow and purple, respectively

In the dot-plot matrix obtained from the comparison between the red jungle fowl and duck TCRY loci (Fig. 4B), we can clearly find that there was no region longer than $5 \mathrm{~kb}$ with high level of pairwise identity in the 5' part of the TCRy loci between chicken and duck, but the $\mathrm{J} \gamma-\mathrm{C}_{\gamma}$ regions of chicken and duck show higher nucleotide identity, indicating that the $\mathrm{J}_{\gamma}-\mathrm{C} \gamma$ region remains conserved in Anas and Gallus during birds evolution. However, this homology portion is interrupted due to insertion of a fragment containing J $\gamma 4$ and J $\gamma 5$ segments in duck. Phylogenetic analysis of the chicken and duck $J \gamma$ segments shows that the chicken $J \gamma 1$, J $\gamma 2$ and $\mathrm{J} \gamma 3$ segments are tightly clustered with the duck J $\gamma 1$, J $\gamma 2$ and J $\gamma 3$ segments, respectively (see Additional file 6), but the duck JY4 and J $\gamma 5$ segments which have nearly identical nucleotide sequences seem to have no corresponding $J \gamma$ segment in chicken but are clustered with chicken/duck J $\gamma 3$ with a relatively low bootstrap percentage $(53 \%)$, suggesting that either J $\gamma 4$ or J $\gamma 5$ might first evolve from a duplication of the J $\gamma 3$ occurred earlier after the speciation of Anas and Gallus, and this $\mathrm{J \gamma}$ duplicated again to form current J $\gamma 4$ and J $\gamma 5$ segments in duck $T C R \gamma$ locus.

\section{Expression of chicken TCRY gene in various tissues}

The expression profile of chicken $T C R \gamma$ genes in different tissues, which were sampled from Hy-line Brown hens at the ages of 30 days and 300 days, was assessed by qRT-PCR. In 30-days-old chickens (Fig. 5A), TCRy was highly expressed in the thymus and spleen, and relatively weakly in the lung and gut. In 300-days-old chickens (Fig. 5B), TCRY was also highly expressed in the thymus and spleen, and the expression in the lung and gut seemed to be higher than that in the 30-days-old chickens. The relatively lower expression of TCRY in gut may probably be attributed to the tissue for RNA extraction is the gut wall but not the gut epithelium where the chicken $\gamma \delta \mathrm{T}$ cells are mainly found [38]. Unexpectedly, in 300-days-old laying hens, TCR $\gamma$ was still expressed at the highest level in the thymus. The TCRy expression 

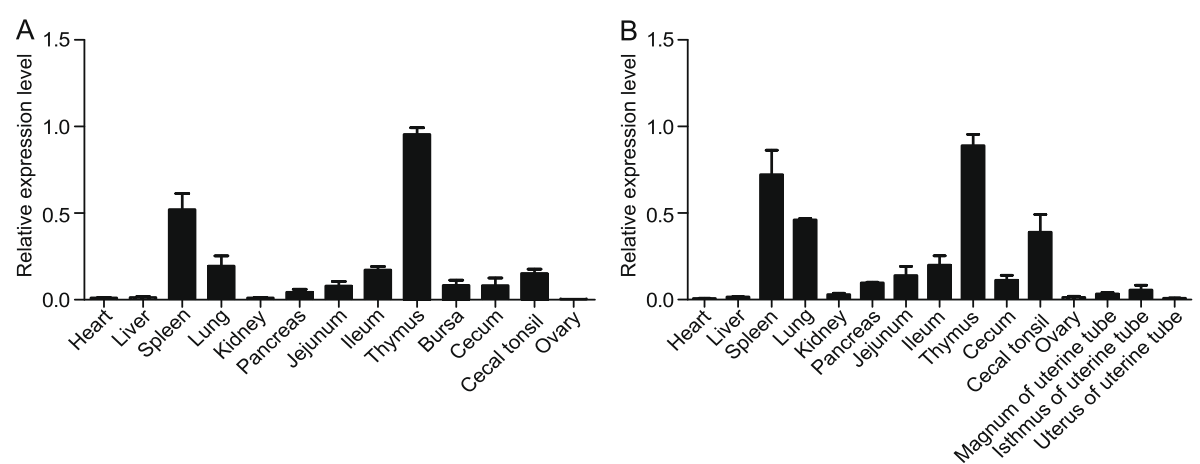

Fig. $\mathbf{5}$ The relative expression levels of TCRy gene in different tissues. qRT-PCR analysis of the relative expression levels of TCRy gene in different tissues of Hy-line Brown hens aged 30 days (A) and 300 days (B). The chicken GAPDH gene was selected as an internal control. The vertical axis indicates the normalized fold changes in expression calculated using the $2^{-\Delta \Delta C t}$ method, and the tissues are listed below the horizontal axis. Data are representative of four independent samples, and the error bar represents the standard deviation of the mean

level did not decrease due to thymic degeneration as expected, and the reason of this phenomenon need to be further explored.

\section{Diversity of $T C R Y$ transcripts in chicken thymus}

Based on 5' RACE assay and HTS, we analyzed the TCR $\gamma$ repertoire from thymus of four 30-days old Hyline Brown hen. A total of 200,114, 121,916, 105,939 and
170,315 unique V-region nucleotide sequences were obtained from four samples, respectively. By alignment of each unique $\mathrm{V}$-region sequence with the germline $\mathrm{V}_{\gamma}$ and $\mathrm{J} \gamma$ sequences identified in red jungle fowl $T C R \gamma$ locus, 369, 222, 235 and 324 sequences that utilized pseudo- or ORF- germline $\mathrm{V} \gamma_{\gamma}$ segments were filtered from four samples, respectively, and the rest TCR $\gamma$ transcripts $(199,745, \quad 121,694, \quad 105,704$ and 169,991

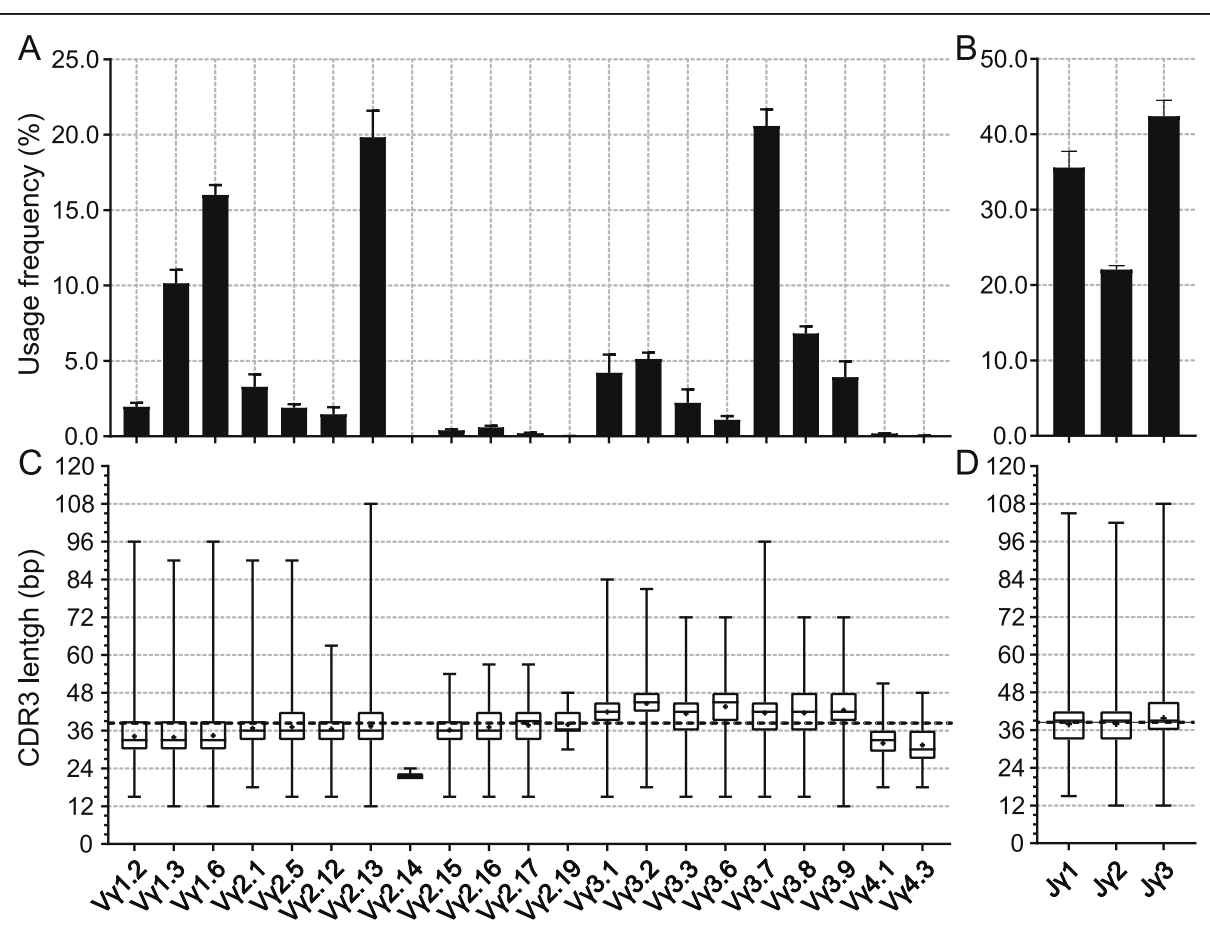

Fig. 6 Usage frequency of each $V_{Y}$ and $J_{Y}$ segment and their corresponding mean CDR3Y length. The usage frequencies of each $V_{Y}$ and $J_{Y}$ segment are shown in figure $\mathbf{A}$ and $\mathbf{B}$, and the mean nucleotide length of CDR3 $\gamma$ corresponding to each $V_{\gamma}$ and Jy segment are shown in figure $\mathbf{C}$ and $\mathbf{D}$. In figure $\mathbf{C}$ and $\mathbf{D}$, the boxplots represent the nucleotide length distribution of CDR3Y (including the sum of all functional CDR3Y sequences from four individuals) for each $V_{Y}$ and $J_{y}$ segment. The upper and lower ends of a rectangular box represent the third quartile and first quartile of the CDR3y length, respectively. The horizontal line and the plus sign inside the box indicate the median and the mean of the CDR3y length, respectively. The black dotted line represents the mean length of CDR3y (38.68 bp) calculated from all functional CDR3ץ sequences 
sequences) were analyzed the combinational diversity. In general, all four $V_{\gamma}$ subgroups containing potentially functional $\mathrm{V}_{\gamma}$ segments participated in $\mathrm{V}_{\gamma}-\mathrm{J} \gamma$ rearrangement (Fig. 6A). Members of $\mathrm{V} \gamma 3$ subgroup (43.98\%) appeared to be more frequently utilized than those of $\mathrm{V} \gamma 1$ $(28.12 \%)$ and $V \gamma 2(27.68 \%)$ subgroups (data not shown). There was also a usage preference of several $\mathrm{V}_{\gamma}$ segments, including $\mathrm{V} \gamma 3.7, \mathrm{~V} \gamma 2.13, \mathrm{~V} \gamma 1.6$ and $\mathrm{V} \gamma 1.3$, which account for $20.58 \%, 19.84 \%, 16.00$ and $10.15 \%$ of the expressed $V_{\gamma}$ repertoire, respectively. The two functional members of $V_{\gamma} 4$ subgroup, $V_{\gamma} 4.1$ and $V_{\gamma} 4.3$, took part in V-J rearrangement but with very low frequencies (0.19 and $0.03 \%)$, which is probably the reason why this subgroup has not been identified by traditional cloning and sequencing methods. All three $J \gamma$ gene segments were utilized in $\mathrm{V} \gamma-\mathrm{J} \gamma$ rearrangement, with a little biased usage of $\mathrm{J} \gamma 3$ segment (42.38\%) compared with $\mathrm{J} \gamma 1$ $(35.58 \%)$ and JY2 (22.04\%) segments (Fig. 6B). Combinations of the above dominantly expressed $\mathrm{V}_{\gamma}$ and $\mathrm{J \gamma}$ segments formed several favoured $\mathrm{V}_{\gamma}-\mathrm{J} \gamma$ pairs (Fig. 7). The V $33.7-\mathrm{J} \gamma 3$ was most frequently used pair with $10.67 \%$ percent in all combinations, and the top six pairs, including $\mathrm{V} \gamma 2.13-\mathrm{J} \gamma 1, \mathrm{~V} \gamma 2.13-\mathrm{J} \gamma 3, \mathrm{~V} \gamma 1.6-\mathrm{J} \gamma 3$, $\mathrm{V} \gamma 3.7-\mathrm{J} \gamma 1$ and $\mathrm{V} \gamma 1.6-\mathrm{J} \gamma 1$, totally accounted for more than $44 \%$ of the entire repertoire. No dominantly deviation was observed in comparison of preferred $\mathrm{V} \gamma-\mathrm{J} \gamma$ pairs between individuals (see Additional file 7).

\begin{tabular}{|c|c|c|c|c|}
\hline Vy1.2 - & 0.6081 & 0.5629 & 0.8372 & \multirow{22}{*}{$\begin{array}{l}-{ }_{-10.0}^{10.0} \\
-{ }_{0}^{5.0} \\
\text { Percent }\end{array}$} \\
\hline Vy1.3 - & 2.9191 & 2.9961 & 4.3873 & \\
\hline Vy1.6 - & 5.6478 & 3.9968 & 6.2217 & \\
\hline Vy2.1- & 2.3951 & 0.5217 & 0.2721 & \\
\hline Vy2.5 - & 0.5228 & 0.3823 & 0.9753 & \\
\hline Vy2.12 & 0.5170 & 0.2957 & 0.5485 & \\
\hline Vy2.13- & 8.5398 & 3.6213 & 7.4007 & \\
\hline Vy2.14- & 0.0007 & 0 & 0.0005 & \\
\hline Vy2.15- & 0.2040 & 0.0883 & 0.1228 & \\
\hline Vy2.16- & 0.1130 & 0.1089 & 0.3855 & \\
\hline Vy2.17 - & 0.0608 & 0.0400 & 0.0956 & \\
\hline Vy2.19- & 0.0039 & 0.0020 & 0.0033 & \\
\hline Vy3.1- & 1.5303 & 0.9306 & 1.9972 & \\
\hline Vy3.2 - & 2.6374 & 1.0912 & 1.4158 & \\
\hline Vy3.3 - & 0.5804 & 0.4007 & 1.4117 & \\
\hline Vy3.6 - & 0.1733 & 0.3229 & 0.6344 & \\
\hline Vy3.7 - & 5.7453 & 4.2526 & 10.6706 & \\
\hline Vy3.8 - & 3.3239 & 1.3448 & 2.1848 & \\
\hline Vy3.9- & 0.5181 & 0.9661 & 2.2556 & \\
\hline Vy4.1- & 0.0385 & 0.0556 & 0.0891 & \\
\hline \multirow[t]{2}{*}{ Vy4.3 - } & 0.0054 & 0.0089 & 0.0162 & \\
\hline & Jy1 & Jy2 & Jy3 & \\
\hline \multicolumn{5}{|c|}{$\begin{array}{l}\text { Fig. } 7 \text { Usage frequencies of all possible } V_{Y}-J y \text { pairs. The vertical axis } \\
\text { represents all potentially functional } V_{Y} \text { segments and the horizontal } \\
\text { axis represents three } J y \text { segments. The color depth is proportional to } \\
\text { the usage frequency of a certain } V_{Y-J Y} \text { pair }\end{array}$} \\
\hline
\end{tabular}

To identify the junctional diversity of the rearranged $T C R \gamma$ transcripts, we first filtered the sequences containing putatively non-functional CDR3 region. After filtering, 183,476, 112,860, 97,203 and 156,224 sequences containing functional CDR3 region were retained from four samples, respectively, which account for $91.86 \% \sim 92.74 \%$ of the unique V-region sequences rearranged from functional $\mathrm{V}_{\gamma}$ and $\mathrm{J}_{\gamma}$ (data not shown). These sequences were used to analyze the length distribution and AA composition of the CDR3y. The diversity of $T C R \gamma$ CDR3 is generated not only by $\mathrm{V}_{\gamma}-\mathrm{J} \gamma$ rearrangement but also by the insertions of non-templated $(\mathrm{N})$ and palindromic $(\mathrm{P})$ nucleotides during the recombination process. $\mathrm{N}$ and $\mathrm{P}$ nucleotides as well as the exonuclease removals at the $3^{\prime}$ end of $\mathrm{V}$ segments and 5' end of $J$ segments were very common. For the potentially functional clones, the mean length of CDR3 was $38.69 \pm 7.06 \mathrm{bp}$ that encoded 4 to 36 (mean 12.90) AA (Fig. 8). Among them, more than $99.97 \%$ of the unique CDR3y sequences encoded 4 to $22 \mathrm{AA}$, which forms a typical Gaussian distribution. The lengths of CDR3 $\gamma$ formed by different V-J combinations showed marked differences (Fig. 6C, D). For $\mathrm{V}_{\gamma}$ segments, members of subgroup $\mathrm{V} \gamma 3$ tended to form longer CDR3 $\gamma$ (mean $42.45 \mathrm{bp}$ ) than the other three subgroups (mean 34.13, 35.39 and $31.67 \mathrm{bp}$, for $\mathrm{V}_{\gamma} 1, \mathrm{~V}_{\gamma} 2$ and $\mathrm{V}_{\gamma} 4$, respectively), probably because the germline CDR3 of $\mathrm{V} \gamma 3(23 \mathrm{bp})$ is longer than those of $V_{\gamma} 1(15 \mathrm{bp}), \mathrm{V}_{\gamma} 2(15 \mathrm{bp})$ and $\mathrm{V}_{\gamma} 4$ (13 bp). For the same reason, Jy3 formed longer CDR3s (mean $39.76 \mathrm{bp}$ ) than $\mathrm{J} \gamma 1$ (mean $37.84 \mathrm{bp}$ ) and $\mathrm{J} \gamma 2$ (mean $37.93 \mathrm{bp}$ ). Furthermore, $\mathrm{V} \gamma 3$ segments prefer to combine with $\mathrm{J} \gamma 3(46.34 \%)$ than the $\mathrm{V} \gamma 1$ and $\mathrm{V} \gamma 2$ segments (32.69 and 20.97\%) (see Additional file 8), also leading to form longer CDR3s.

\section{Discussion}

The TCRY locus is the smallest and least complex of the three conventional TCR loci and most considerably differ across species. By annotating the latest assembly of the red jungle fowl genome sequences, we found that chicken $T C R \gamma$ locus spans about $100 \mathrm{~kb}$, which is similar with opossum (90 kb), dromedary (105 kb), Chinese alligator $(115 \mathrm{~kb})$ and Rhesus monkey $(120 \mathrm{~kb})$, larger than dolphin $(60 \mathrm{~kb})$ and rabbit $(70 \mathrm{~kb})$ but smaller than human (160 kb), mouse (205 kb), sheep (250 kb, two loci), cat (260 kb), Atlantic salmon (270 kb, two loci), bovine (316 kb, two loci) and dog (460 kb) [20, 22-33]. As is reported in a previous study by Liu and colleagues [9], the immediately flanking the 3 ' terminal of the $T C R \gamma$ locus is a LRRFIP2 (LRR binding FLII interacting protein 2) gene. However, the immediately flanking the $5^{\prime}$ terminal of this locus is an $A M P H$ (amphiphysin) gene in the current genome sequence but a PRKDC (protein kinase 


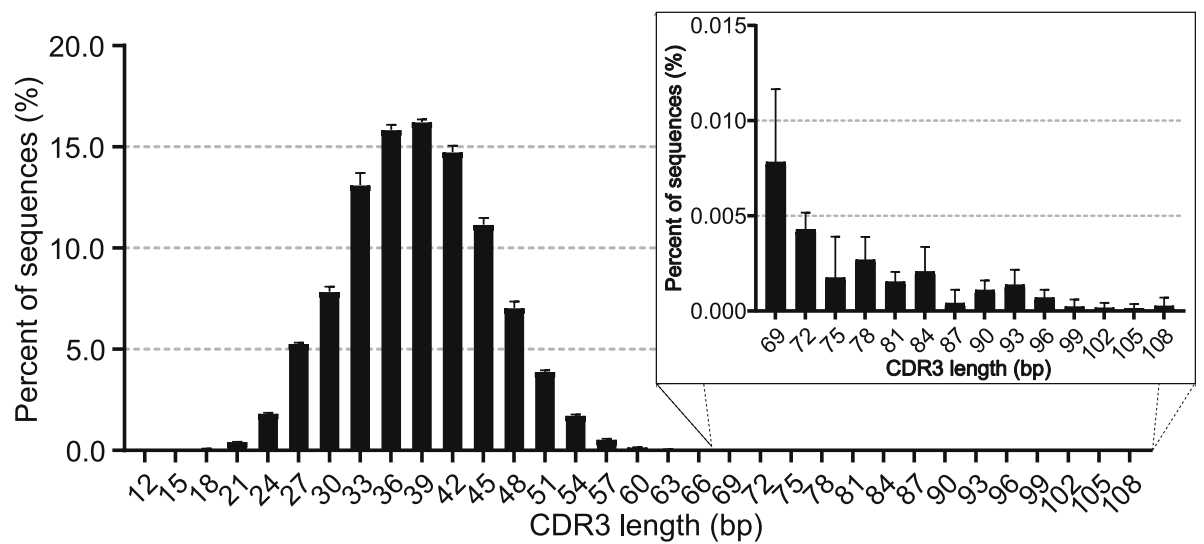

Fig. 8 Length distribution of CDR3y. The nucleotides encoding the 2nd-conserved cysteine and the conserved phenylalanine are not included in the CDR3y. The horizontal axis represents the nucleotide length of CDR3y region. The bar height indicates the mean frequency from four individuals, and the error bars show standard deviations

DNA-activated catalytic polypeptide) gene in the previous study [9]. It is unclear which gene is correct, but a conserved $A M P H$ gene was also identified at the same location flanking the $T C R \gamma$ loci of many other species, such as human, mouse, opossum, rabbit, Chinese alligator, Rhesus monkey, dromedary, dolphin, cat and dog [20, 22, 24-26, 30-32, 39]. Although the chicken TCR $\gamma$ locus is relatively smaller, it contains most (44) germline $\mathrm{V} \gamma$ segments compared with species which have definite genomic maps of TCRY loci [20-33]. Interestingly, the percentage of potentially functional $\mathrm{V}_{\gamma}$ genes in chicken is $63.64 \%$ ( 28 of the $44 \mathrm{~V} \gamma$ ), which seems to be similar to human (6 of $14 \mathrm{~V} \gamma, 42.86 \%$ ), cat (6 of $12 \mathrm{~V} \gamma, 50 \%$ ), $\operatorname{dog}(8$ of $16 \mathrm{V \gamma}, 50 \%)$, duck (8 of $15 \mathrm{~V} \gamma, 53.33 \%$ ), Atlantic salmon (7 of $11 \mathrm{~V} \gamma, 63.64 \%$ ) and rabbit (8 of 11 $\mathrm{V} \gamma, 72.73 \%$ ) and lower than sheep (11 of $13 \mathrm{~V} \gamma$, $84.62 \%$ ), dromedary (6 of $7 \mathrm{~V} \gamma, 85.71 \%$ ), Chinese alligator (16 of $18 \mathrm{V \gamma}, 88.89 \%)$, bovine (16 of $17 \mathrm{~V} \gamma, 94.12 \%$ ), mouse (7 of $7 \mathrm{V \gamma}, 100 \%$ ) and opossum (9 of $9 \mathrm{~V} \gamma, 100 \%$ ) [20-30, 32, 33, 40]. Liu and colleagues previously identified $37 \mathrm{~V} \gamma$ segments in chicken TCRY locus, which could be divided into 11 subgroups [9]. Due to absence of the germline sequence of each $V_{\gamma}$ in that study, we cannot establish the one-to-one correspondence between the $V_{\gamma}$ segments identified in the present and previous studies. However, according to the mallard $V_{\gamma}$ sequences used in phylogenetic tree in that study, we can speculate the possible corresponding relationship between the six $\mathrm{V}_{\gamma}$ subgroups identified now and the $11 \mathrm{~V} \gamma$ subgroups identified previously (designated as $\operatorname{preV} \gamma 1$ to preV $\gamma 11$ ) [9]. In detail, $\mathrm{V} \gamma 1$ and $\mathrm{V} \gamma 5$ probably corresponds to $\mathrm{preV}_{\gamma} 1$; $\mathrm{V} \gamma 2$ probably corresponds to $\operatorname{preV} \gamma 3,4,5,6,7,9,10$ and $11 ; \mathrm{V} \gamma 3$ probably corresponds to $\operatorname{preV}_{\gamma} 2$; and $\mathrm{V}_{\gamma} 4$ and $\mathrm{V} \gamma 6$ probably corresponds to $\operatorname{preV} \gamma 8$.

Unlike $\alpha \beta$ T cells that require peripheral activation for differentiation into different effector cells, $\gamma \delta \mathrm{T}$ cells can be "developmentally programmed" in the thymus to generate different effector subsets. The thymic commitment to a $\gamma \delta \mathrm{T}$ cell fate at least in part requires the signal delivered by its $\gamma \delta$ TCR [41]. In mice and humans, functionally distinct $\gamma \delta \mathrm{T}$ cell subsets can be defined by certain $\mathrm{V}_{\gamma}$ region (in mice) or $\mathrm{V} \delta$ region (in humans) that each subset expresses, [41-43]. During ontogeny of mice, waves of $\gamma \delta \mathrm{T}$ cell subsets possessing subsetcharacteristic $\mathrm{V} \gamma_{\gamma}$ (and sometimes pairing with certain Vס) regions are successively generated in the thymus. Especially during fetal and early newborn life, several $\gamma \delta$ $\mathrm{T}$ cell subsets containing invariant (or semi-invariant) $\gamma \delta$ TCRs develop and acquire programmed effector functions in the thymus. After leaving the thymus, each $\gamma \delta \mathrm{T}$ cell subset migrates to distinct anatomical locations and performs particular functions [41-43]. Of note, in comparison with chicken, the germline repertoire of $\mathrm{V}_{\gamma}$ segments available for rearrangement is quite restricted in both humans and mice. In humans, only six to eight functional $\mathrm{V}_{\gamma}$ segments from two $\mathrm{V}_{\gamma}$ subgroups can be utilized in productively rearrangement [27, 40]. Although mice $\mathrm{V}_{\gamma}$ segments can be divided into five subgroups, except $V_{\gamma} 1$ subgroup which has three functional $V_{\gamma}$ segments, only one functional $V_{\gamma}$ segment has been identified in each subgroup from $V_{\gamma} 2$ to $\mathrm{V} \gamma 5$ [28]. From this point view, the potentially combinational diversity of $T C R \gamma$ is lower in humans and mice than in chickens, in which at least $21 \mathrm{~V} \gamma_{\gamma}$ segments from four $V_{\gamma}$ subgroups are available for rearrangement in the present study. Furthermore, a preference of $\mathrm{V} \gamma 3.7$, $V_{\gamma} 2.13, V_{\gamma} 1.6$ and $V_{\gamma} 1.3$ segments is also a notable feature of the combinational diversity of $T C R \gamma$ in chicken thymus. This feature was observed in all four 30-daysold individuals, indicating that this preference may be "developmentally programmed" in the thymus. Perhaps similarly to mice, certain chicken $V_{\gamma}$-specific TCRs 
(maybe also pairing with certain $\mathrm{V} \delta$ ) might induce the acquisition of particular effector phenotypes at particular anatomical locations in the chicken, which is worthy of further study.

The length distribution of the CDR3 has been used as a metric in assessments of the possible range of binding paratope generated by a given TCR type. By either traditional cloning and sequencing (hereafter called lowthroughput sequencing, LTS) or HTS, the length distribution of the CDR3Y (AA numbers) has been analyzed in the following species, including humans: 4 to 15 (mean 10.2) AA by LTS and 6 to 20 AA by HTS [4447]; mice: 7 to 14 (mean 11.8) AA by LTS and 6 to 16 AA by HTS [44, 48]; ducks: 5 to 19 (mean 11.0) AA by LTS [21]; platypus (Ornithorhynchus anatinus): 9 to 15 AA by LTS [37]; Chinese alligator: 4 to 17 (mean 11.3) AA by LTS [22]; Florida manatee (Trichechus manatus latirostris): 5 to 21 (mean 10.6) AA by HTS [49]; nurse shark (Ginglymostoma cirratum): 9 to 15 (mean 12.1) AA by LTS [50] and Japanese flounder (Paralichthys olivaceus): 8 to 13 (mean 11.5) AA by LTS [51]. In this study, we obtained a more accurate length distribution of the chicken CDR3y based on HTS. The vast majority of the chicken CDR3y sequences encoded 4 to 22 with mean $12.90 \mathrm{AA}$, which exhibits a wider length distribution and/or a longer mean length than the data from most other species mentioned above, indicating that this vast length variability would markedly increase the sequence/structural diversity of chicken TCRy chains, which could presumably affect pairing with the TCR $\delta$ chain and downstream signaling or effector functions. By HTS, we also found 138 "ultralong CDR3y (23 to 36 AA), though they just account for less than $0.025 \%$ of the total CDR3y sequences. The AA composition of the normal CDR3y (4 to $22 \mathrm{AA}$ ) and ultralong CDR3y were analyzed separately (Fig. 9). Compared with normal

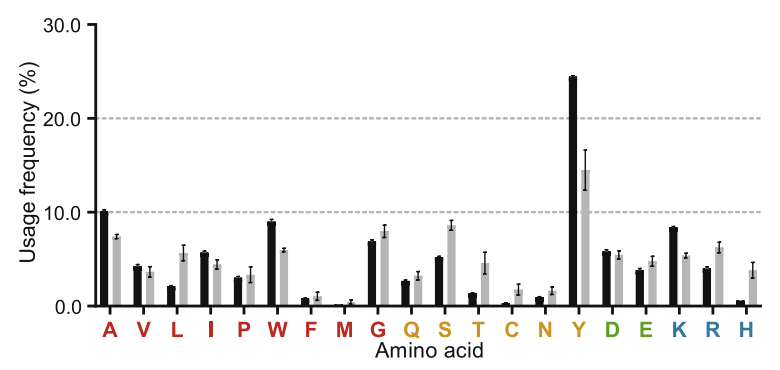

Fig. 9 Composition of twenty essential amino acids in the CDR3ץ. Hydrophobic, neutral-hydrophilic, acidic and basic amino acids are depicted below the horizontal axis in red, yellow, green and blue, respectively. Black and gray columns represent the mean frequency of certain amino acid calculated from normal CDR3Y (4 to $22 \mathrm{AA}$ ) and ultralong CDR3y (23 to $36 \mathrm{AA}$ ), respectively. The mean frequency was calculated from four individuals, and the error bars show standard deviations
CDR3y, ultralong CDR3y tended to use less hydrophobic AA $(42.20 \%$ vs. $39.96 \%)$, but more hydrophilic AA (57.80\% vs. $60.04 \%)$. The tyrosine content of ultralong CDR3y (14.50\%) was significantly lower than that of normal CDR3y (24.46\%), but the usage of other neutral and hydrophilic AA (including serine, threonine, asparagine and glutamine) in ultralong CDR3 $\gamma$ was higher than that in normal CDR3y (Fig. 9). These results indicated that the ultralong CDR3 $\gamma$ might form unusual architecture for antigen binding. We also found that the cysteine residue was strongly preferred in ultralong CDR3y than normal CDR3y (1.76\% vs. $0.33 \%)$, suggesting that the ultralong CDR3y might use interloop disulfide bond to maintain the structural stability of the long CDR3y loop.

Finally, earlier studies of chicken $\mathrm{T}$ cell development indicated that the chicken thymus is colonized with thymocyte precursors in three discrete waves during embryogenesis [52]. The $\gamma \delta \mathrm{T}$ cells produced from each wave exit rapidly from the thymus without undergoing clonal expansion and colonize peripheral organs such as spleen and intestine [38]. By using semiquantitative PCR and LTS of the TCR $\gamma$ transcripts, subsequent studies showed that although the precursors of each wave rearranged all three subgroups (subgroup $V_{\gamma} 1$ to $V \gamma 3$ ) identified then, each wave displayed a variable repertoire, indicating that the repertoire diversities of TCR $\gamma$ in the thymus are likely to change with ontogeny of chicken [53]. In this study, we only focused on the $T C R \gamma$ repertoire acquired from the thymus of 30-days-old hens, and future research can use HTS to survey the repertoire diversities of TCRy in both thymus and peripheral lymphoid tissues during the ontogeny of chicken, which may contribute to discover the similarities and differences in development of the gd $\mathrm{T}$ cells between birds and mammals or between " $\gamma \delta$-low" and " $\gamma \delta$-high" species.

\section{Conclusions}

In this study, we analyzed the chicken thymus $T C R \gamma$ repertoire based on the germline $\mathrm{V}_{\gamma}$ and $\mathrm{J}_{\gamma}$ segments identified in the latest assembly of the red jungle fowl genome sequences (GRCg6a). The notable features of chicken thymus $T C R \gamma$ repertoire include a biased usage of several $\mathrm{V}_{\gamma}$ segments and $\mathrm{V}_{\gamma}-\mathrm{J}_{\gamma}$ pairs, as well as a wider length distribution of the CDR3y. We hope that our characterization of chicken $T C R \gamma$ repertoire can widen the understanding of adaptive immunology in birds and benefit future research on adaptive immune responses of chicken in health and disease.

\footnotetext{
Abbreviations

TCR: T cell receptor; RACE: Rapid Amplification of cDNA Ends; HTS: Highthroughput sequencing; CDR3: Complementarity-determining region 3; CD3: Cluster of differentiation 3; MHC: Major histocompatibility complex; IMGT: The international ImMunoGeneTics information system; BAC: Bacterial artificial chromosome; SMRT: Single molecule real time sequencing technology; RSS: Recombination signal sequence; ORF: Open reading
} 
framework; Phe: Phenylalanine; Gly: Glycine; Tyr: Tyrosine; His: Histidine; CYS: Cysteine; TRP: Tryptophan; FR: Framework region; qRT-PCR: Quantitative real-time polymerase chain reaction; AA: Amino acids; 3' UTR: 3' untranslated region

\section{Supplementary Information}

The online version contains supplementary material available at https://doi. org/10.1186/s12864-021-07975-7.

Additional file 1. The accession numbers of $V_{Y}$ segments used in phylogenetic analysis.

Additional file 2. Primers used in this study.

Additional file 3. Phylogenetic analysis of members from $V_{\gamma} 2$ subgroup. The phylogenetic tree was constructed using the Neighbor Joining method in MEGA $X$ with nucleotide sequences corresponding to FR1 through FR3. Bootstrap percentage values based on 1000 replicates are shown at the interior branch nodes.

Additional file 4. Detailed information of the germline $V_{\gamma}$, J $\gamma$, and $C_{\gamma}$ gene segments retrieved from genomic sequences of red jungle fowl (GRCg6a).

Additional file 5. Nucleotide sequence similarities between homology units by pairwise alignment.

Additional file 6. Phylogenetic analysis of Jy segments from chicken and duck. The phylogenetic tree was constructed using the Maximum likelihood method in MEGA $X$ with nucleotide sequences of Jy segments. Bootstrap percentage values based on 1000 replicates are shown at the interior branch nodes. Chicken Jy segments are shown in bold.

Additional file 7. Usage frequencies of all possible $V_{Y}-J_{Y}$ pairs in each individual. The vertical axis represents all potentially functional $V_{Y}$ segments and the horizontal axis represents three Jy segments. The color depth is proportional to the usage frequency of a certain $V_{Y}-J Y$ pair.

Additional file 8. Usage frequencies of three $J_{Y}$ segments paired with different $V_{Y}$ subgroups.

\section{Acknowledgements}

Not applicable.

\section{Authors' contributions}

TZ, QL and XL performed research; YS designed research; TZ analyzed data; YS and TZ wrote the paper; YJ improved the manuscript. All authors read and approved the final manuscript.

\section{Funding}

This work was supported by the National Natural Science Foundation of China [grant number 31501943].

\section{Availability of data and materials}

The raw sequence reads generated from HTS were submitted to Sequence Read Archive (SRA) database (accession number: PRJNA714701,https://www. ncbi.nlm.nih.gov/sra/PRJNA714701).

\section{Declarations}

\section{Ethics approval and consent to participate}

All animal experiments in the present study were approved by the Institutional Animal Care and Use Ethics Committee of Shandong Agricultural University (Permit Number: NO. 2007005). The animal experiments were performed in accordance with the Guidelines for Experimental Animals of the Ministry of Science and Technology (Beijing, China), and in compliance with ARRIVE 2.0 Essential 10 guidelines [54].

\section{Consent for publication}

Not applicable.

\section{Competing interests}

The authors declare that they have no competing interests.
Received: 24 March 2021 Accepted: 1 September 2021

Published online: 21 September 2021

\section{References}

1. Reddy ST. The patterns of T-cell target recognition. Nature. 2017:547:36.

2. Davis MM, Bjorkman PJ. T-cell antigen receptor genes and T-cell recognition. Nature. 1988;334(6181):395-402.

3. Hou X, Wang M, Lu C, Xie Q, Cui G, Chen J, Du Y, Dai Y, Diao H. Analysis of the Repertoire Features of TCR Beta Chain CDR3 in Human by HighThroughput Sequencing. Cell Physiol Biochem. 2016;39(2):651-67.

4. Benichou J, Ben-Hamo R, Louzoun Y, Efroni S. Rep-SEq. uncovering the immunological repertoire through next-generation sequencing. Immunology. 2012;135(3):183-91.

5. Chien YH, Meyer C, Bonneville M. gamma delta T Cells: first line of defense and beyond. Annu Rev Immuno. 2014;32:121-55.

6. Cooper MD, Chen CL, Bucy RP, Thompson CB. Avian T cell ontogeny. Adv Immunol. 1991;50:87-117.

7. IMGT ${ }^{\oplus}$, the international ImMunoGeneTics information system ${ }^{\oplus}$. http://www. imgt.org. Accessed 12 Mar 2021.

8. Six A, Rast JP, McCormack WT, Dunon D, Courtois D, Li Y, Chen CH, Cooper MD. Characterization of avian T-cell receptor gamma genes. Proc Natl Acad Sci U S A. 1996;93(26):15329-34.

9. Liu F, Li J, Lin IYC, Yang X, Ma J, Chen Y, Lv N, Shi Y, Gao GF, Zhu B. The Genome Resequencing of TCR Loci in Gallus gallus Revealed Their Distinct Evolutionary Features in Avians. Immunohorizons. 2020;4(1):33-46.

10. Chicken genomic sequences (GRCg6a) GenBank database. https://www. ncbi.nlm.nih.gov/assembly/GCF_000002315.5/. Accessed 17 Oct 2018.

11. IGBLAST. https://www.ncbi.n/m.nih.gov/igblast/. Accessed 17 Oct 2018.

12. Giudicelli $V$, Lefranc M-P. Ontology for immunogenetics: the IMGTONTOLOGY. Bioinformatics. 1999:15(12):1047-54.

13. Lefranc M-P, Pommié C, Ruiz M, Giudicelli V, Foulquier E, Truong $L$, Thouvenin-Contet $V$, Lefranc G. IMGT unique numbering for immunoglobulin and T cell receptor variable domains and Ig superfamily Vlike domains. Dev Comp Immunol. 2003;27(1):55-77.

14. Burland TG. DNASTAR's lasergene sequence analysis software. Methods $\mathrm{Mol}$ Biol. 2000;132:71-91.

15. Nicholas K, Nicholas H. GeneDoc: a tool for editing and annotating multiple sequence alignments. 1997.

16. Kumar S, Stecher G, Li M, Knyaz C, Tamura K. MEGA X: molecular evolutionary genetics analysis across computing platforms. Mol Biol Evol. 2018;35(6):1547-9.

17. dotmatcher. http://emboss.bioinformatics.nl/cgi-bin/emboss/dotmatcher/. Accessed 9 Jan 2019.

18. Mamedov IZ, Britanova OV, Zvyagin IV, Turchaninova MA, Bolotin DA, Putintseva EV, Lebedev YB, Chudakov DM. Preparing unbiased T-cell receptor and antibody cDNA libraries for the deep next generation sequencing profiling. Front Immunol. 2013;4:456.

19. Martin M. Cutadapt removes adapter sequences from high-throughput sequencing reads. EMBnet.journal. 2011;17(1):10-2.

20. Parra ZE, Baker ML, Hathaway J, Lopez AM, Trujillo J, Sharp A, Miller RD. Comparative genomic analysis and evolution of the T cell receptor loci in the opossum Monodelphis domestica. BMC Genomics. 2008;9:111.

21. Yang Z, Sun Y, Ma Y, Li Z, Zhao Y, Ren L, Han H, Jiang Y, Zhao Y. A comprehensive analysis of the germline and expressed TCR repertoire in White Peking duck. Sci Rep. 2017;7:41426.

22. Wang XF, Wang $P$, Wang RP, Wang CL, Bai JH, Ke CC, Yu D, Li KP, Ma YH, Han HT, Zhao YF, Zhou X, Ren LM. Analysis of TCR beta and TCR gamma genes in Chinese alligator provides insights into the evolution of TCR genes in jawed vertebrates. Dev Comp Immunol. 2018;85:31-43.

23. Conrad ML, Mawer MA, Lefranc MP, McKinnell L, Whitehead J, Davis SK, Pettman R, Koop BF. The genomic sequence of the bovine T cell receptor gamma TRG loci and localization of the TRGC5 cassette. Vet Immunol Immunopathol. 2007;115(3-4):346-56.

24. Massari S, Bellahcene F, Vaccarelli G, Carelli G, Mineccia M, Lefranc MP, Antonacci R, Ciccarese S. The deduced structure of the T cell receptor gamma locus in Canis lupus familiaris. Mol Immunol. 2009; 46(13):2728-36.

25. Massari S, Ciccarese S, Antonacci R. Structural and comparative analysis of the T cell receptor gamma (TRG) locus in Oryctolagus cuniculus. Immunogenetics. 2012;64(10):773-9.

26. Giudicelli V, Duroux P, Ginestoux C, Folch G, Jabado-Michaloud J, Chaume $D$, Lefranc MP. IMGT/LIGM-DB, the IMGT comprehensive database of 
immunoglobulin and T cell receptor nucleotide sequences. Nucleic Acids Res. 2006;34(Database issue):D781-784.

27. Lefranc M-P, Chuchana P, Dariavach P, Nguyen C, Huck S, Brockly F, Jordan $B$, Lefranc $G$. Molecular mapping of the human T cell receptor gamma (TRG) genes and linkage of the variable and constant regions. Eur J Immunol. 1989;19(6):989-94.

28. Vernooij BTM, Lenstra JA, Wang K, Hood L. Organization of the Murine TCell Receptor Locus. Genomics. 1993;17(3):566-74.

29. Vaccarelli G, Miccoli MC, Antonacci R, Pesole G, Ciccarese S. Genomic organization and recombinational unit duplication-driven evolution of ovine and bovine T cell receptor gamma loci. BMC Genomics. 2008;9:81.

30. Radtanakatikanon A, Keller SM, Darzentas N, Moore PF, Folch G, Nguefack Ngoune V, Lefranc MP, Vernau W. Topology and expressed repertoire of the Felis catus T cell receptor loci. BMC Genomics. 2020;21(1):20.

31. Linguiti G, Antonacci R, Tasco G, Grande F, Casadio R, Massari S, Castelli V, Consiglio A, Lefranc MP, Ciccarese S. Genomic and expression analyses of Tursiops truncatus T cell receptor gamma (TRG) and alpha/delta (TRA/TRD) loci reveal a similar basic public gamma delta repertoire in dolphin and human. BMC Genomics. 2016;17(1):778.

32. Antonacci R, Linguiti G, Burger PA, Castelli V, Pala A, Fitak R, Massari S, Ciccarese $\mathrm{S}$. Comprehensive genomic analysis of the dromedary $T$ cell receptor gamma (TRG) locus and identification of a functional TRGC5 cassette. Dev Comp Immunol. 2020;106:103614.

33. Yazawa R, Cooper GA, Beetz-Sargent M, Robb A, McKinnel L, Davidson WS, Koop BF. Functional adaptive diversity of the Atlantic salmon T-cell receptor gamma locus. Mol Immunol. 2008;45(8):2150-7.

34. Ma JP, Yang X, LV N, Liu F, Chen Y, Zhu BL. [Re-sequencing and assembly of chicken T cell receptor gamma locus]. Yi Chuan. 2015;37(6):568-74.

35. Göbel TW, Chen CL, Lahti J, Kubota T, Kuo CL, Aebersold R, Hood L, Cooper MD. Identification of T-cell receptor alpha-chain genes in the chicken. Proc Natl Acad Sci. 1994;91:1094-8.

36. Zhang T, Liu G, Wei Z, Wang Y, Kang L, Jiang Y, Sun Y. Genomic organization of the chicken TCRbeta locus originated by duplication of a Vbeta segment combined with a trypsinogen gene. Vet Immunol Immunopathol. 2020;219:109974.

37. Parra ZE, Arnold T, Nowak MA, Hellman L, Miller RD. TCR gamma chain diversity in the spleen of the duckbill platypus (Ornithorhynchus anatinus). Dev Comp Immunol. 2006;30(8):699-710.

38. Bucy RP, Chen CL, Cihak J, Losch U, Cooper MD. Avian T cells expressing gamma delta receptors localize in the splenic sinusoids and the intestinal epithelium. J Immunol. 1988;141(7):2200-5.

39. Glusman G, Rowen L, Lee I, Boysen C, Roach JC, Smit AF, Wang K, Koop BF, Hood L. Comparative genomics of the human and mouse T cell receptor loci. Immunity. 2001;15(3):337-49.

40. Zhang XM, Tonnelle $\mathrm{C}$, Lefranc MP, Huck S. T cell receptor gamma CDNA in human fetal liver and thymus: variable regions of gamma chains are restricted to $\mathrm{V}$ gamma I or $\mathrm{V}$, due to the absence of splicing of the $\mathrm{V} 10$ and V11 leader intron. Eur J Immunol. 1994;24(3):571-8.

41. Munoz-Ruiz M, Sumaria N, Pennington DJ, Silva-Santos B. Thymic Determinants of gammadelta T Cell Differentiation. Trends Immunol. 2017; 38(5):336-44.

42. O'Brien RL, Born WK. gammadelta T cell subsets: a link between TCR and function? Semin Immunol. 2010;22(4):193-8.

43. Vermijlen D, Prinz I. Ontogeny of Innate T Lymphocytes - Some Innate Lymphocytes are More Innate than Others. Front Immunol. 2014;5:486.

44. Rock EP, Sibbald PR, Davis MM, Chien YH. CDR3 length in antigen-specific immune receptors. J Exp Med. 1994;179(1):323-8.

45. Davey MS, Willcox CR, Joyce SP, Ladell K, Kasatskaya SA, McLaren JE, Hunter S, Salim M, Mohammed F, Price DA, Chudakov DM, Willcox BE. Clonal selection in the human Vdelta1 T cell repertoire indicates gammadelta TCRdependent adaptive immune surveillance. Nat Commun. 2017;8:14760.

46. Arruda LCM, Gaballa A, Uhlin M. Graft gammadelta TCR Sequencing Identifies Public Clonotypes Associated with Hematopoietic Stem Cell Transplantation Efficacy in Acute Myeloid Leukemia Patients and Unravels Cytomegalovirus Impact on Repertoire Distribution. J Immunol. 2019;202(6): 1859-70.

47. Djaoud Z, Parham P. Dimorphism in the TCRgamma-chain repertoire defines 2 types of human immunity to Epstein-Barr virus. Blood Adv. 2020; 4(7):1198-205.
48. Fahl SP, Coffey F, Kain L, Zarin P, Dunbrack RL Jr., Teyton L, Zuniga-Pflucker $J C$, Kappes DJ, Wiest DL. Role of a selecting ligand in shaping the murine gammadelta-TCR repertoire. Proc Natl Acad Sci U S A. 2018;115(8):1889-94.

49. Breaux B, Hunter ME, Cruz-Schneider MP, Sena L, Bonde RK, Criscitiello MF. The Florida manatee (Trichechus manatus latirostris) T cell receptor loci exhibit V subgroup synteny and chain-specific evolution. Dev Comp Immunol. 2018:85:71-85.

50. Criscitiello MF, Ohta Y, Saltis M, McKinney EC, Flajnik MF. Evolutionarily conserved TCR binding sites, identification of T cells in primary lymphoid tissues, and surprising trans-rearrangements in nurse shark. J Immunol. 2010;184(12):6950-60

51. Nam BH, Hirono I, Aoki T. The four TCR genes of teleost fish: the CDNA and genomic DNA analysis of Japanese flounder (Paralichthys olivaceus) TCR alpha-, beta-, gamma-, and delta-chains. J Immunol. 2003;170(6):3081-90.

52. Coltey M, Jotereau FV, Le Douarin NM. Evidence for a cyclic renewal of lymphocyte precursor cells in the embryonic chick thymus. Cell Differ. 1987; 22(1):71-82.

53. Dunon D, Courtois D, Vainio O, Six A, Chen CH, Cooper MD, Dangy JP, Imhof BA. Ontogeny of the immune system: gamma/delta and alpha/beta T cells migrate from thymus to the periphery in alternating waves. J Exp Med. 1997;186(7):977-88.

54. Percie du Sert N, Hurst V, Ahluwalia A, Alam S, Avey MT, Baker M, Browne WJ, Clark A, Cuthill IC, Dirnagl U, Emerson M, Garner P, Holgate ST, Howells DW, Karp NA, Lazic SE, Lidster K, MacCallum CJ, Macleod M, Pearl EJ, Petersen OH, Rawle F, Reynolds P, Rooney K, Sena ES, Silberberg SD, Steckler T, Wurbel $H$. The ARRIVE guidelines 2.0: Updated guidelines for reporting animal research. PLoS Biol. 2020;18(7):e3000410.

\section{Publisher's Note}

Springer Nature remains neutral with regard to jurisdictional claims in published maps and institutional affiliations.
Ready to submit your research? Choose BMC and benefit from:

- fast, convenient online submission

- thorough peer review by experienced researchers in your field

- rapid publication on acceptance

- support for research data, including large and complex data types

- gold Open Access which fosters wider collaboration and increased citations

- maximum visibility for your research: over $100 \mathrm{M}$ website views per year

At BMC, research is always in progress.

Learn more biomedcentral.com/submissions 